\title{
Power Quality Improvement in Distributed Generation using DSTATCOM and Photovoltaic Power Controller
}

\author{
Vinay Keswani, Dr Arun.K.Mitra
}

\begin{abstract}
Conventional energy sources like coal, nuclear energy sources, water, and other fossil fuels are getting depleted day by day. The availability of these resources is limited and would be exhausted one day. Therefore people have recently started to use renewable energy sources like sun, wind and tidal energy for electrical power generation. The electricity generators which are mounted within the premises of consumers or in the vicinity of load are known as Distributed Generation resources. One of the abundant available energy resources is sun. The sunlight available from sun as expected would last for millions of years. The sunlight can be converted to electrical energy using Photovoltaics. The PV Panels mounted on the rooftops can convert sunlight to electrical energy. These PV panels contain small devices called as solar cells. The PV source is also connected to the utility grid through suitable Power Electronic Interfaces. The PV panels are distributed randomly in each phase. Sometimes the power from PV source in one phase can exceed the power generated from the grid in that phase. This excess power can flow from the point of common coupling towards the substation and can cause unbalance in the three phase currents of the transmission line. This Paper outlines a technique wherein a Distributed Static Compensator (DSTACOM) is connected to the grid which will take the unbalanced three phase currents of the transmission line, process the currents and inject currents back in the transmission line so as to make the three phase currents balanced, thus balancing the three phase power.
\end{abstract}

Keywords: DSTATCOM, DVR, Reverse Power Flow, PV, Distributed Generation

\section{Manuscript received November 20, 2019}

Vinay Keswani, Electrical Engineering, Vidarbha Institute of Technology, Nagpur, Maharashtra, India, +917719943213, (e-mail: vinaykeswani2009@yahoo.com)

Dr. Arun K. Mitra, Electronics Engineering, Manoharbhai Patel Institute of Engineering and Technology, Gondia, Maharashtra, India, +91371177520
The other objective of the paper is to achieve voltage stability at the point of coupling of the PV system and the Grid. The irradiance from the Sun varies throughout the day, thus changing the voltage at the point of common coupling. The switching pulses provided to the semiconductor switches used in the Power Electronic Interface are adjusted by a Fuzzy Logic Controller so as to control the reactive power injected into the transmission line, thus achieving the Voltage Stability.

\section{INTRODUCTION}

Photovoltaic is one of the most recent sources of electrical energy used currently. The solar panels consist of solar cells which are connected in series and parallel to form modules. Each solar cell is nothing but a PN junction consisting of space charge layer having a inbuilt Voltage of $0.7 \mathrm{~V}$ in Silicon and $0.6 \mathrm{~V}$ in Germanium. The equivalent model of solar cell consists of current source, a diode and series and shunt resistances. Thus practically a solar cell acts as a current source. When sun- light falls on solar cell, the energetic photons because of their energy give rise to charge carriers ie electrons and holes. These charge carriers are separated by inbuilt voltage of the cell and give rise to solar current. Each solar cell gives a voltage in the range of 0.6$0.7 \mathrm{~V}$ which is a dc voltage. The solar cells are connected in series to increase the level of voltage to a suitable value and each string of solar cells is connected with another string to have strings in parallel to increase the level of current thus forming panels. Since solar panels give rise to dc voltage, the solar panels cannot be directly interfaced with the consumer loads as the loads require alternating source of energy. The dc voltage obtained from solar panel is increased to a suitable level by a boost converter employing semiconductor switches. For each solar cell there is a set of IV curves. Corresponding to each value of current and voltage one can obtain certain power from the solar cell. The objective while using PV Panels is to obtain Maximum Power Output from it. The Maximum Power Point Tracking system uses certain techniques to obtain Maximum Power from Solar Panels. The PV system uses Power Electronic Interfaces like inverters for connecting the PV system to the grid. Suitable filters containing capacitors and filters are employed at the output of inverter bridges to eliminate the harmonics while interfacing with the grid. 


\section{LITERATURE REVIEW}

Jing Li, Fang Zhuo, Xianwei Wang, Lin Wang, Song Ni in [1] "A Grid-Connected PV System with Power Quality Improvement Based on Boost + Dual-Level Four-Leg Inverter have proposed a research, which not only allows a wide range of input voltage, but also compensates unbalance current of the local load in three-phase three-wire PV system with the help Dual-Level Four Leg Inverter.

Work by V. Hima Leela, S. Thai Subha in [2] "Control of Power Converter for Power Quality Improvement in a Grid Connected PV System focuses on the design, modeling and control of power converters for power quality improvement in a grid connected Distributed Generator system. In this paper Photovoltaic is considered as DG. All the simulations are carried out in MATLAB/Simulink environment and. the results with priggish analysis are exhibited.

Xiaoqing Han, Ruifen Cheng, Peng Wang, Yanbing Jia in [3] "Advanced Dynamic Voltage Restorer to Improve Power Quality in Microgrid" have introduced a device namely dynamic voltage restorer (DVR) based on photovoltaic (PV) generation/battery units to improve voltage quality in a microgrid. The restorer is connected with the grid by a rectifier, which is in series with the point of common coupling (PCC). Using energy management system (EMS), the proposed apparatus could be operated under dynamic voltage restorer mode, uninterrupted power supply mode and micro-source mode, and be switched smoothly among them. The dynamic voltage restorer could handle voltage sag or surge, and thus improves the power quality in microgrid

Hamad, M.S, Fahmy, A.M, and Abdel- Geliel, M in [4] Power Quality Improvement of a Single- Phase GridConnected PV System with Fuzzy MPPT Controller have worked on Photovoltaic (PV) systems which are gridconnected via an interfacing converter which operates with Maximum Power Point Tracking (MPPT) controller in order to feed the grid by the maximum allowable solar power. In this paper, the PV interfacing inverter is controlled using a predictive control technique to perform both functions of power quality improvement in addition to transferring the PV maximum power to the grid. A Fuzzy logic control algorithm is applied for MPPT.

Meenakshi Jayaraman1, Sreedevi V.T. and Rajkiran Balakrishnan in [5] "Analysis and Design of Passive Filters for Power Quality Improvement in Standalone PV Systems" have used passive filters which include LC, LCL and LLCC filter topologies. A comparison study of the total harmonic distortion reduction with the above filters is done. Further, the paper attempts to show that the use of LLCC filter with a standalone PV system can highly improve the power quality of the system. Results are verified using simulations in MATLAB-SIMULINK environment.

Digvijay B Kanase A. R Thorat H. T Jadhav in [6] in" Distribution Static compensator for Power Quality Improvement using PV Array" have pro- posed distribution static compensator for improvement of power quality using PV cell. Dstatcom is used for reducing the reactive power that resulted from various types of load on the distribution systems. The Dstatcom is used for compensating harmonics at PCC.

\section{PROPOSED SYSTEM}

The model designed using Simulink in Matlab is shown in fig 1 . The proposed system consists of three phase generator generating voltage at $66 \mathrm{KV}$ line to line. This voltage is stepped down by a three phase step down transformer. The grid is connected to three phase R-L-C Load at the extreme right. To introduce unbalance in currents in the transmission line because of reverse power flow due to excess power generation, a fault generator is connected in the transmission line. Using this block a line- line, Line-Ground or LineLine- Line fault can be introduced in the transmission line. This unbalance in currents can be viewed in scope block as shown in the figure 1 . The DSTACOM connected in the transmission line will inject currents in the transmission line in such a way so as to remove the unbalance in the currents and hence power unbalance will be eliminated. The DSTATCOM block consists of two three phase Rectifier/Inverter bridges connected in parallel as shown in fig2. The output of the upper bridge 1 is connected to DC link which is a capacitor here. The upper three phase bridge acts a rectifier to which three phase input is given from the transmission line. 
International Journal of Innovative Research in Computer Science \& Technology (IJIRCST)

ISSN: 2347-5552, Volume-7, Issue-6, November 2019

https://doi.org/10.21276/ijircst.2019.7.6.3

www.ijircst.org

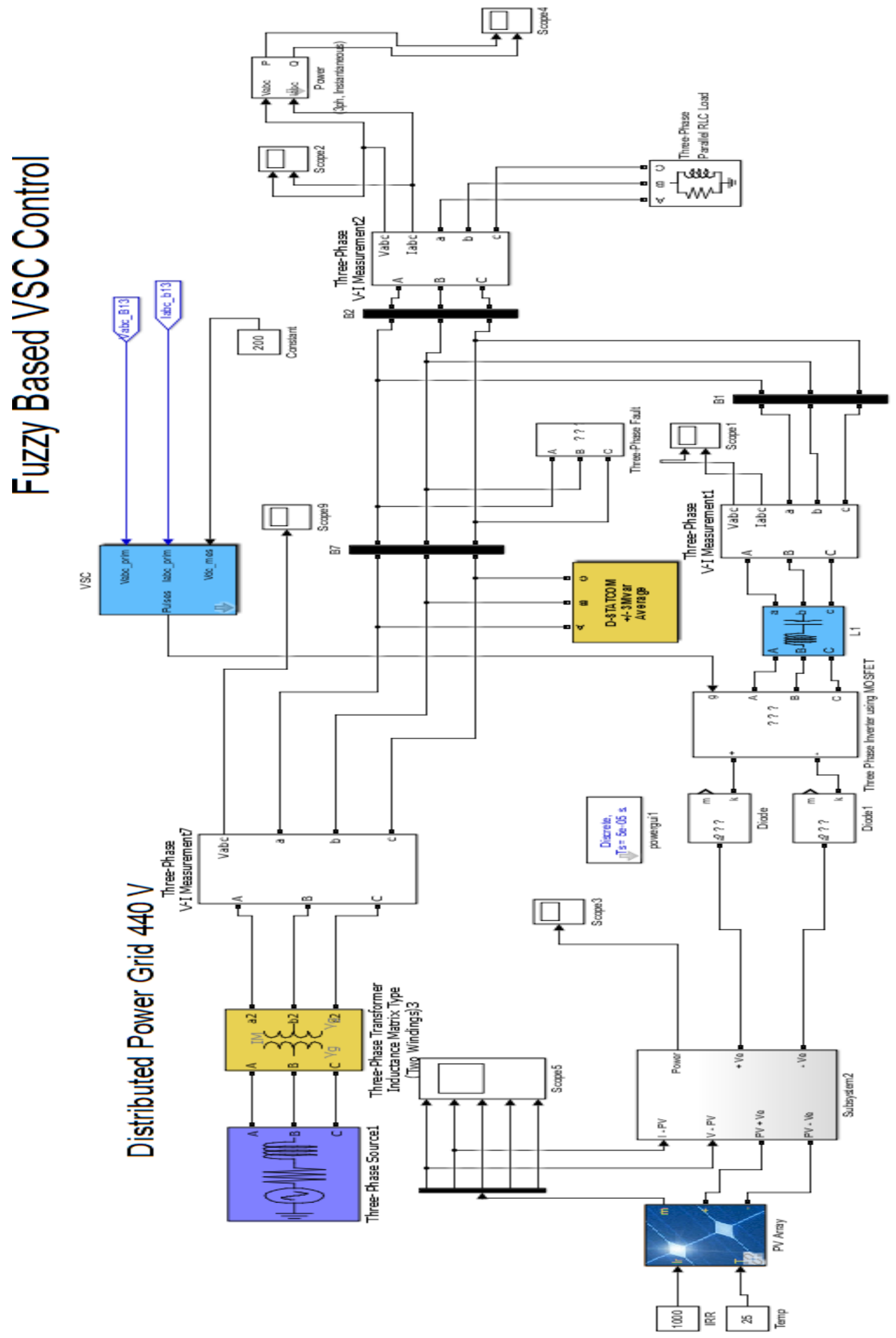

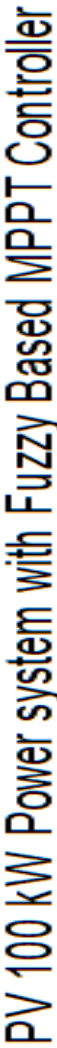

Fig 1: PV System with Grid and DSTATCOM 


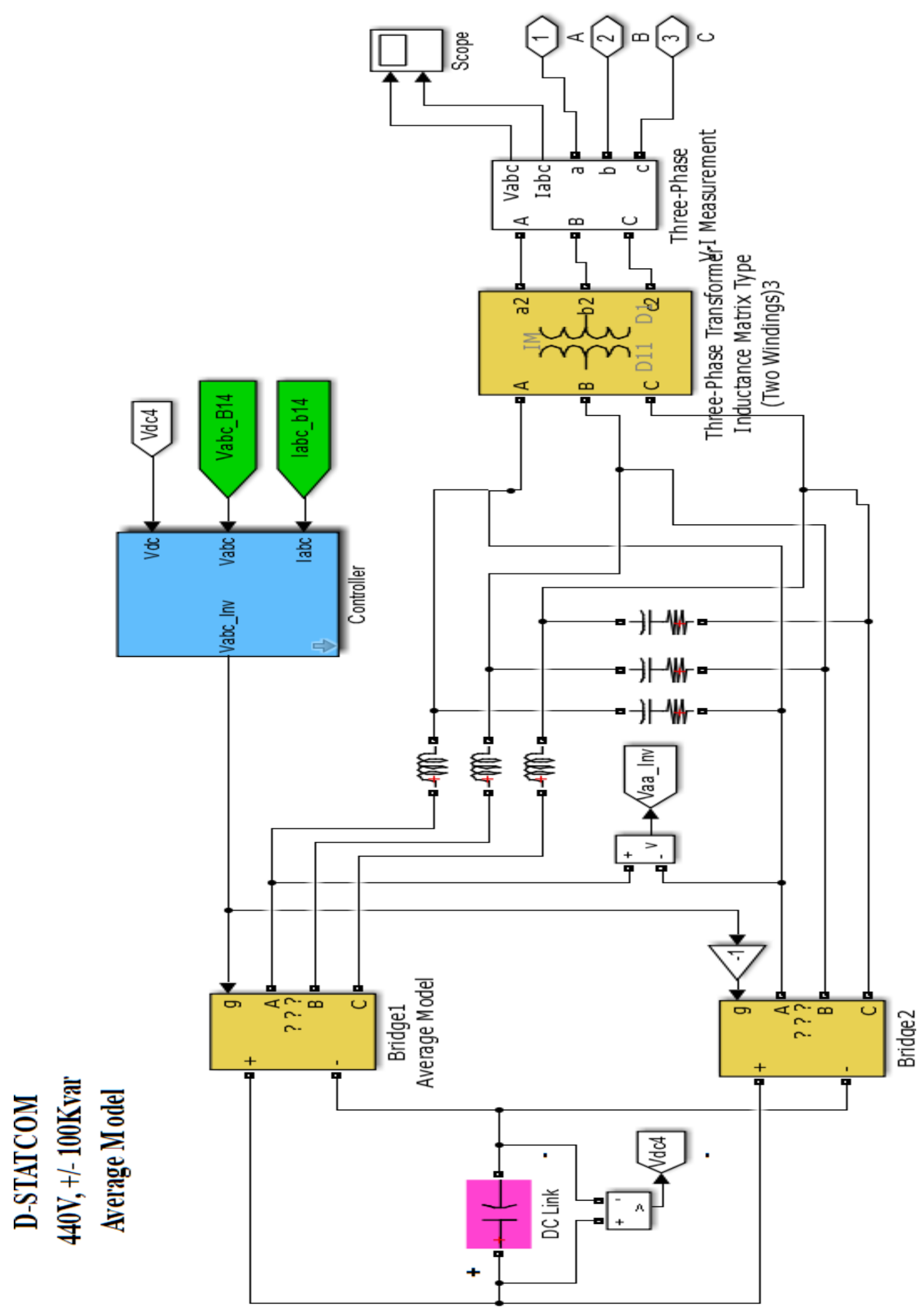

Fig 2: DSTATCOM 
The semiconductor switches in the rectifier bridge are controlled by a controller which controls their gating pulses so that DC voltage at the output of the bridge charges the capacitor. This DC link voltage available across the capacitor goes as input to the Three Phase Inverter bridge which is the lower bridge 2 and inverted pulses are applied to the gates of the semiconductor switches in this bridge. The gating pulses applied to the semiconductor switches of the lower bridge 2 are so controlled by a controller shown in fig 2 so that the injected current into the transmission line balances the three phase currents. The balanced current after connecting the DSTATCOM can be viewed through scope in Fig1

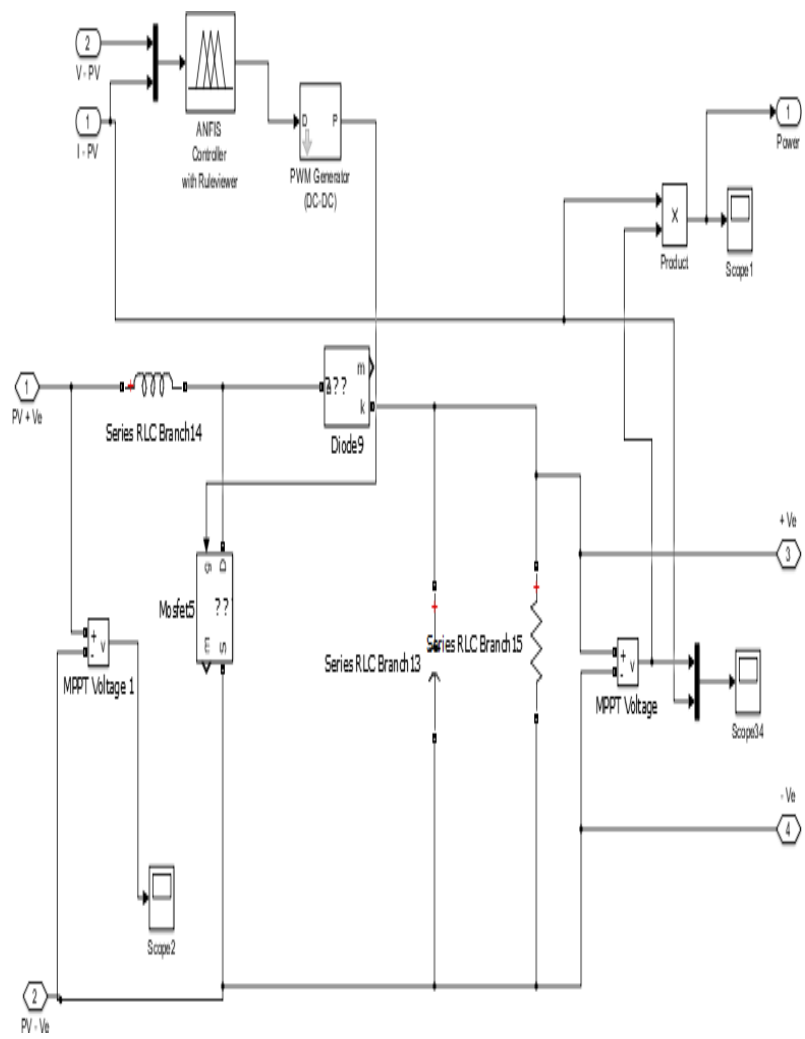

Fig 3: Boost Converter with MPPT Fuzzy Logic Controller

The other objective of the paper of voltage stability is also achieved by the above simulink model shown in Fig1. The PV Array has input irradiance of $1000 \mathrm{~W} / \mathrm{m}^{2}$ and temperature is maintained at 25 degree celsius. The output of PV Array block is given to DEMUX which gives four outputs as provided by PV Array. These outputs are Current, Voltage, Irradiance and Diode Current. The Sub- system 2 consists of a process which uses Fuzzy Controller to extract maximum power output from the values of $\mathrm{I}$ and $\mathrm{V}$ provided. The voltage at which extracted power is maximum is fed to the three phase inverter which converts DC to three phase $\mathrm{AC}$ output which is connected to grid after filtering through a transformer. The simulink model showing MPPT Fuzzy logic controller is shown in fig 3. The gating pulses to the three phase inverter are controlled by a Fuzzy Logic Controller so that the inverter injects controlled reactive power at the point of coupling with the grid thereby achieving voltage stability.

\section{CONCLUSION}

The paper describes a technique to remove the unbalance in currents in the transmission line because of reverse power flow due to excess power generation at the point of PV coupling to the grid. The voltage reliability issues because of unpredictable behavior of sun irradiance are overcome by employing Fuzzy Logic Controller which controls the gating pulses of switching devices of Three Phase Inverter thereby controlling the reactive power injected into the transmission line at the point of coupling with the grid. Thus improving voltage stability

\section{REFERENCES}

[1] Jing Li, Fang Zhuo, Xianwei Wang, Lin Wang, Song $\mathrm{Ni}$ "A Grid-Connected PV System with Power Quality Improvement Based on Boost + Dual-Level Four-Leg Inverter, 2009 IEEE.

[2] V. Hima Leela, S. Thai Subha "Control of Power Converter for Power Quality Improvement in a Grid Connected PV System”, 2013 IEEE

[3] Xiaoqing Han, Ruifen Cheng, Peng Wang, Yanbing IEEE.

[4] Hamad, M.S, Fahmy, A.M, and Abdel-Geliel "Power Quality Jia "Advanced Dynamic Voltage Restorer To Improve Power Quality In Microgrid", 2013 Improvement of a Single-Phase Grid- Connected PV System with Fuzzy MPPT Controller”, 2013 IEEE.

[5] Meenakshi Jayaraman1, Sreedevi V.T.and Rajkiran Balakrishnan "Analysis and Design of Passive Filters for Power Quality Improvement in Standalone PV Systems" 2013 Nirma University International Conference on Engineering (NUiCONE)

[6] Digvijay B Kanase A. R Thorat, H. T Jadhav " Distribution Static compensator for Power Quality Improvement using PV Array", 2015 IEEE.

[7] Seyyed Abbas Saremi Hasari, Ali Rasoolzadeh Akhijahani, Alunad Salemnia "Power Loss Reduction and Power Quality Improvement in Distribution Systems Using a Modified Converter, 2015 IEEE 